\title{
Psychological Preparedness of Journalists Covering Emergencies and the Aspects of its Socio-Psychological Impact on Society
}

\begin{abstract}
The article touches upon the need for psychological preparedness of journalists working in emergencies supported by the results of an experiment. During the experiment, we used well-known methods. Our findings suggest that it is necessary to incorporate the programme "Psychological Preparedness of Journalists Covering Emergencies" into the curriculum of those educational institutions where Journalism is taught. It will significantly reduce the risks and the negative impact of emergencies first of all on journalists and then on the audience through the information provided by journalists.
\end{abstract}

Keywords: emergencies, psychological preparedness of journalists, personal factors, personal characteristics and socio-psychological preparedness of journalists working in emergencies, perception and transfer of information, research, experience, retesting, professional education program, curriculum.

\section{Introduction and literature review}

The issues of social and psychological preparedness of journalists covering emergencies and developing ways to resolve them are relevant especially today, in the $21^{\text {st }}$ century, when, on the one hand, the number and diversity of emergencies increased, and, on the other hand, much more importance is given to their coverage. In our days, when the "most expensive" product in this "rapidly shrinking" the world is information, when it is possible to not only instantly receive data in any part of the world but also disseminate it, to work in "live" format, quite frequently journalists, not even realising and imagining the subtleties of working in emergencies, its psychological aspects, and specific strict professional rules, often not having the necessary professional and psychological preparedness, do not stand the temptation, make unreasonable steps and get targeted by terrorists, military activists, hostage-takers, thus risking both their own lives and the future article they are going to write, which might be of high importance.

This is why the research covered in the article is more than relevant today, especially when speaking about a country that shares borders with at least two hostile neighbouring 
states - within an unsolved conflict - and within the boundaries of which we can still see peaceful civilians and children being shot under armed antagonism. Despite the fact that Armenia is situated in a seismic zone - thus, under a perpetual risk of earthquakes, even with the negative experience of a terror attack at the Parliament causing unprecedented damage to the prospects of the country (October 27, 1999), and though any other situation might be observed as of gravity, for instance, the armed assault and seizure of the Police Patrol Service regiment in Yerevan, Armenia (July 16, 2016), we selected journalists with previous and current work experience in military areas as the target group for the research within the scope of this article: their daily work directly impacts the public mood, and they are also involved in the information war, thus, forming a prevailing mood in the region.

Emergencies are inevitable phenomena, which not only disrupt the natural pace of development of societies but may also leave a deep trace on specific layers of society, thus jeopardising their physical and psychological well-state.

An emergency is a situation in a specific area caused by natural and human-made disasters or other hazardous phenomena which causes loss of life, health detriments, property damage, or environmental damage, behavioural changes both at individual and group levels. The adverse effects at the group level have an impact both on sociopsychological phenomena and on the crowd, which directly affects individuals and groups who are performing professional activities in these conditions. Such situations disrupt both the ordinary course of life for individuals and the population and their professional activity, at the same time affecting their mental condition.

Emergency conditions are characterised by changes in the information structure, social and psychological limitations and presence of danger: an individual is affected by psychological factors, which results in emotional outbursts if he/she is poorly prepared. From a psychological point of view, emergencies are characterised as substantial factors affecting an individual's mental health. They can be healthy and intense, characterised by varying degrees of unexpectedness and scale, and can become both a subjective and objective cause of stress. Emergencies change the psychological side of one's activity by introducing new requirements for a person's adaptation.

Today, as a rule, information about an emergency prevails over coverage of other events. The priority of such information forms the mass consciousness adaptation effect in regards to disasters and the inevitability thereof. As a result of all this, society lacks an adequate perception of safe behaviour in emergencies. However, no society is free of various disasters and emergencies that are unpredictable, uncontrollable, and 
unmanageable. In this regards, the psychological preparedness of specialists directly dealing with the public in emergency situations is essential. This mainly refers to specialists who have a particular, broad audience and hold the full range of measures to influence the general public. This may refer to mass media reporters.

The Armenian society pays insufficient attention to the role and meaning of mass media in emergency situations; moreover, the aspect of psychological impact on a journalist covering emergency and the issue of psychological influence spread to the broader public by the affected journalist have not been duly studied yet. In fact, by acting as a social regulator for the public, mass media does not support the socio-psychological stability of society in emergency conditions and does not serve one of their primary objectives - caring for mass consciousness with the help of reporting specialists.

Accordingly, there is a necessity to create a psychological training system for journalists. The psychological preparedness of journalists is particularly crucial, first of all, for ensuring journalists' well-being and for maintaining their harmonious state of mind as very often they need psychological support while working under extreme circumstances.

This is the first-ever attempt in Armenian journalism to identify the psychological preparedness of journalists working in emergencies, as well as the psychological impact of emergency situations on journalists. Likewise, the matter of psychological impact caused by the information provided by journalists to the population is also brought up.

The subject of this research refers to the social and psychological analysis of journalists living and working in times of war, and the people living under the impact of the information flow from those journalists, as well as the conclusions made on the basis of this research with regards to the necessity of introducing social-psychological pieces of training for journalists at emergency situations in the Faculty of Journalism.

As a result of regular meetings with journalists working in various Armenian borderline locations and Nagorno-Karabakh territory and experimental studies, a conclusion has been made that a particular level of psychological preparedness for journalists is strongly required to soften the negative impact transferred onto the society.

In the first stage of the two-phased research, we determined the unique characteristics of journalists working in emergencies. In the second phase, we clarified the degrees of expression of those features and their psychological preparedness, as well as conducted a comparative analysis.

We adopted several principles below for the comprehensive study of the subject matter, which were maintained throughout the study:

a) the methods and tasks used did not hurt the dignity of the journalists 
b) mutual respect was maintained

c) the methods have been refined in regards to information

d) the same techniques and methodologies were used with all those participating in the testing, which allowed to compare similar results on various levels

\section{Research Methodology.}

The research activities involved 127 journalists working in emergencies, as well as 104 representatives of both the Armenian and Nagorno-Karabakh populations.

To identify the personal characteristic features of the journalists, the R. Kettle test of "Person's Multi-Functional Research Methods" was applied (16-PF) (1). The test consists of 105 questions.

Likewise, it is assumed that these features must be, to some extent, related to the manifestations of aggression; thus, we used the "Methodology of Diagnosis of Types and Indices of Aggression" by A. Bass and A. Dark (2) within the same research groups.

The analysis shows that in the process of perceiving and transferring information, the person's characteristics and base features, as well as individual psychophysiological peculiarities, expressed through his temperament, self-affirmation, speech and action peculiarities, play a significant role; similarly, high impact is made by the personal and reactive distress, which are the manifestations of fundamental trust towards people and the world. In order to disclose the existence of these factors, the Ch. D. Spielberg and Yu L. Khanin (3) methods were used.

Taylor's "Manifest Anxiety Scale" (MAS) (4;5;6), consisting of 50 statements, was also referred to. It was used for the diagnosis of social adaptation and mental conditions of the population in the following border regions of the Republic of Armenia: a) Tavush Noyemberyan - ljevan - Berd, b) Vayots Dzor - Khachik, c) Syunik -Sisian, and in the Republic of Nagorno-Karabakh: a) Martakert - Mataghis and b) Qarvatchar regions.

During the research, we considered the subject's professional experience and age, even though here, we also focused on the average working age and experience.

In the process of using the "Methodology of Diagnosis of Types and Indices of Aggression" by A. Bass and A. Dark (2), we separated five conditional groups, having worked in emergencies; they were the opposition press, the pro-government press, television and online media, newspapers, and investigating journalists. The last group also involved local journalists from the disaster or war zones.

The research analysis states that the residents of the Armenian border communities and the Nagorno-Karabakh have more noticeably reflected average high alarm level. An 
extremely high alarm level has not been noted. However, certain anxiety and alarm level could still be noticed.

What is more, as a result of the research, it became clear that there was an individual connection between the personal characteristics and social-psychological preparedness of journalists working in emergencies, the impact of information provided to the public by them, the situational conditions, and the selected strategy of behaviour regulation.

Furthermore, as a result of the studies conducted by Kettle's Person's MultiFunctional Research Method (7), we found out the vividly expressed level of selfassessment and low credulity level with weakened concession.

By grouping the personal factors by intellectual, emotional characteristics, peculiarities of communication and interpersonal relations, we may state that the highest rate is expressed by the manifestation of emotional components, playing a significant role in personal characteristics of journalist in emergencies and their social-psychological preparedness, and in the process of impacting the population with the information provided thereby.

The "Methodology of Diagnosis of Types and Indices of Aggression" by A. Bass and A. Dark helped us understand that the journalists had the highest level of guilt, showing 44.32 per cent as to how the society will understand the information they provided and what kind of reaction there will be. The level of nervousness, showing 34.16 per cent, and speech aggression with 32.6 per cent followed. Further, indicators of the level of suspicion with the 32.2 per cent, indirect aggression with 27.2 per cent, and physical aggression with 20.7 per cent were also quite high. Opposite, the negativity and resentment were on quite a low level. Similarly, the experiment showed that the indices of aggression (specifically speech aggression, sense of guilt, nervousness, personal sense of alarm, fluctuating self-esteem scale) also complicated the activities of journalists working in emergencies causing changes in the level of alarm of the subjects.

As a result of studies through the self-assessment diagnosis methodology by Ch. D. Spielberg and Yu. L. Khanin (3), we get a very highly expressed personal and reactive anxiety. The analysis of the research outcomes shows that the inadequate assessment of journalists working in emergencies and insufficiency of social-psychological preparedness results in "personal and reactive alarm".

Following this experiment, the journalists working in emergencies participated in a programme developed by ourselves on "Social-Psychological Preparedness of Journalists Covering Emergencies". Afterwards, we held a retesting process using the 
same methods and methodologies. The retesting showed that certain factors identified in the course of psychological diagnostics were subject to changes in learning the knowledge provided by the programme.

The experiment in question and the outcomes of the retesting serve as proof that after training the journalists with a specific programme, their social-psychological preparedness gets to a level that can already support the fulfilment of the caring function of the profession of journalist. Hence, journalists, first of all, become more protected in emergencies from moral and psychological perspectives. Their articles become more balanced and do not transfer additional negative impact on society.

\section{Conclusion}

The results of the scientific analysis and experimental research of personal characteristics of journalists covering emergencies and their socio-psychological preparedness allow us to draw the following conclusions:

1. The issue of personal characteristics and socio-psychological preparedness of journalists working in emergencies is discussed in different situations; different areas of activity are singled out, taking into account the particularities of each emergency, as well as the objective and subjective factors that significantly influence the personal characteristics and socio-psychological preparedness of journalists and their further development. However, the personal attributes of journalists working in emergencies and the issue of their socio-psychological preparedness still need to be studied since the system, as mentioned above of activity puts forward various psychological requirements in the journalistic field of the Republic of Armenia, which, in turn, give rise to specific psychological difficulties, controversies in relations of journalists working in emergencies, as well as in the process of information provision and social adjustment. Personal characteristics and socio-psychological preparedness of journalists working in emergencies are related to individual factors and behavioural manifestations, which influence the interaction of the subject, social behaviour, and manifestations.

2. There is a particular relationship between personal characteristics and sociopsychological preparedness of journalists working in emergencies, the impact of information they provide to the public, situational conditions and the strategy chosen to regulate behaviour.

3. By personal grouping factors by intellectual, emotional features, peculiarities of communication and interpersonal relations, we can state that the highest indicators are reflected by the presence of emotional components, which have a dominant role in 
personal characteristics of journalists covering emergencies and their socialpsychological preparedness, and in the process of impacting society with the information provided by them. The experiment showed that the indices of aggression (especially the "speech aggression", "sense of guilt", "nervousness", "personal alarm", the fluctuating scale of "self-esteem"), also make the activities of journalists covering emergencies more difficult, complicate the process of providing public with information, resulting in changes of alarm level of the subjects.

4. The results of the research evidence that the emphasised "communicativeness", "expressiveness" and certain mildly reflected manifestations are directly connected with several personal factors, as well as with vividly expressed indicators of "nervousness" which cause "speech aggression" and increase the "sense of guilt".

5. The inadequate assessment of journalists covering emergencies, insufficient level of social-psychological preparedness lead to the state of "anxiety", "personal and reactive alarm", "verbal and non-verbal aggression", thus increasing the indicators of characteristic features of "expressionism", "control" and "sense of guilt".

6. Awareness of programme about personal characteristics of journalists covering emergencies and their social-psychological preparedness allow finding methods and ways out. The organisation of training courses, the increase of certain personal factors, as well as decrease of some of them to a certain extent impact journalists' features of "adaptation", "collaboration", and "compromise". On the other hand, the wide-ranging knowledge thereabout lowers the tendency of creating additional tension in the relations of journalists and society.

7. The retesting showed that some of the factors identified in the course of psychodiagnosis are subject to correction through the knowledge acquired within the framework of the programme.

The devastating earthquake of December 7, 1988, the terrorist attack on the Armenian National Assembly on October 27, 1999, which left eight people killed, including the National Assembly Speaker, two deputy NA Speakers, Prime Minister, a minister and deputies, the seizure of the Police Regiment in Yerevan on July 26, 2016, which left three police officers killed, as well as other emergencies allow confidently asserting that the Armenian journalistic community is doomed to be ready to act safely in emergencies.

Thus, it is necessary to incorporate the programme "Psychological Preparedness of Journalists Covering Emergencies" into the professional education curriculum, especially in $21^{\text {st }}$ century Armenia, where emergencies are inevitable. 


\section{References}

Taylor, J. A. (1951). The relationship of anxiety to the conditioned eyelid response. Journal of Experimental Psychology, 41(2), 8192. https://doi.org/10.1037/h0059488

Taylor, J. A. (1953) A personality scale of manifest anxiety. Journal of Abnormal and Social Psychology, 48, 285-290.

Taylor, J. A. (1956). Drive theory and manifest anxiety. Psychological Bulletin, 53(4), 303-320. https://doi.org/10.1037/h0040353

https://instruct.uwo.ca/kinesiology/9641/Assessments/Psychological/TMAS.html (16.03.2021)

https://people.wku.edu/richard.miller/520\%2016PF\%20Cattell\%20and\%20Mead.pdf (16.03.2021)

https://psycabi.net/testy/293-16-faktornyj-lichnostnyj-oprosnik-r-b-kettella-metodikamnogofaktornyj-oprosnik-kettella-test-kettela-187-voprosov-test-ketela16-pf (16.03.2021)

https://veles-s.ru/en/the-index-of-aggression-bass-black-methods-for-diagnosingindicators-and-forms-of-aggression-a.html (16.03.2021) 